\title{
USE OF IMAGING PLATES IN X-RAY ANALYSIS
}

\author{
M. ERMRICH, F. HAHN and E. R. WÖLFEL(†) \\ STOE \& CIE GmbH, Application Laboratory, Hilpertstraße 10, D-64295 \\ Darmstadt, Germany
}

(Received 18 September 1995)

\begin{abstract}
Two-dimensional detectors have opened a new area for the investigation of both single crystals and polycrystalline materials. The working principle of Imaging Plates is described. Some characteristics and the advantages of an Imaging Plate are discussed using the STOE Imaging Plate Diffraction System for different kinds of X-ray analysis: (i) single crystal diffractometry, (ii) powder diffraction and (iii) stress and texture investigations.
\end{abstract}

KEY WORDS: Imaging plate, powder diffractometry, stress, texture, single crystal diffractometry.

\section{INTRODUCTION}

X-ray diffraction methods for polycrystalline materials and single crystals are nowadays widely used to study material properties and crystal structures. In order to be successful, the sample quality plays an important role. Powdered samples of random orientation and uniform particel size of some $\mu \mathrm{m}$ have to be prepared and powder diffractometers have to provide the necessary sample motions to get accurate results. Untwinned small single crystals have to be grown to be used for structure studies. Thus the preparation of suitable samples still remains a challenge for the chemists.

For the instrument makers the following problems are important: to provide various sample holders with necessary movements for the samples, to improve the flux of the primary beam and to provide detectors which speed up the data collection, to improve peak-to-background ratio, to supply symmetrical peak shapes and if possible to check the sample quality. Last not least a user-friendly software package plays an important role.

STOE has recently developed automated diffractometers for powder and single crystal work which satisfy the above requirements as far as possible. (Wölfel, 1981; Wölfel, 1983; Wölfel et al., 1992; Ermrich and Wölfel, 1994). Here the STOE Imaging Plate Diffraction System (IPDS) will be introduced, see Figure 1, which is primarily designed for single crystal work, but can also be used to characterize both polycrystalline powdered and bulk materials.

\section{PRINCIPLE OF WORK}

Laser stimulated fluorescence image plates have been in use since 1984 as two dimensional area detectors (Miyahara and Kato, 1984; Takahashi et al., 1985). The large dynamic range, high sensitivity and low background renders them ideally suitable as area detectors in $\mathrm{X}$-ray crystallography. 


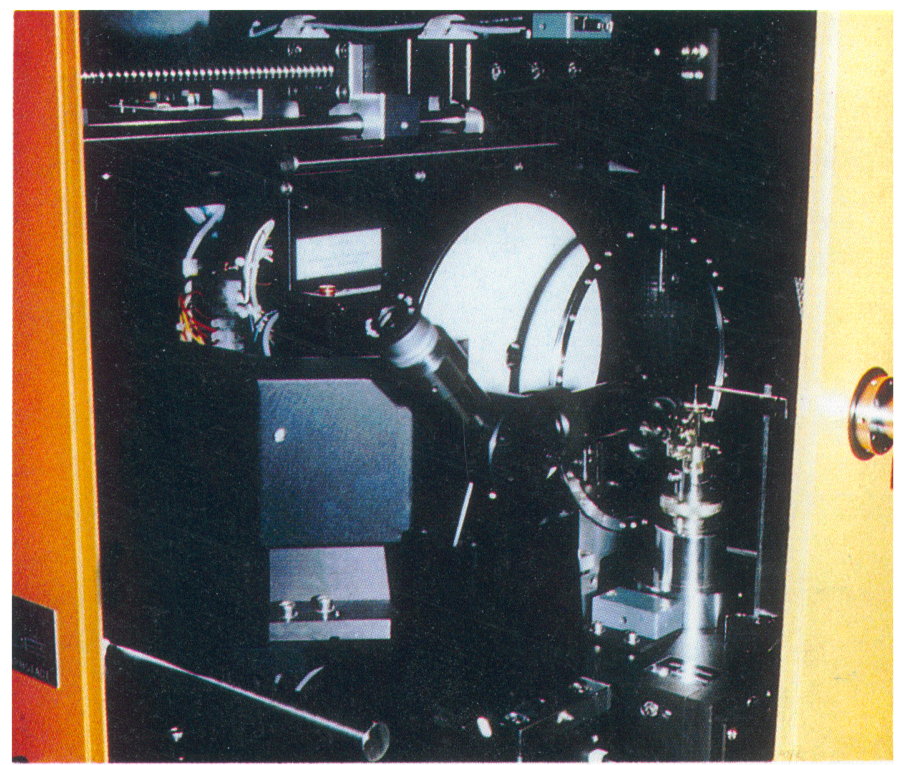

Figure 1 STOE Imaging Plate Diffractometer System (IPDS) with protection casing, goniometer head, microscope and imaging plate. (See Color Plate 9).

The thickness of the whole flexible polyester film is about $0.5 \mathrm{~mm}$. The detection material is the storage phosphor, $\mathrm{BaBrF}: \mathrm{Eu}^{2+}$ grains. Its thickness is about $150 \mu \mathrm{m}$ including the organic binding agent. It is covered by a layer of $10 \mu \mathrm{m}$ polyethylene.

During an exposure the diffraction pattern is stored as a latent image on the plate due to the following mechanism: An X-ray photon hits the storage phosphor. Changing the $\mathrm{Eu}^{2+}$ to $\mathrm{Eu}^{3+}$ an electron goes to the conduction band. Then it traps in a Bromide vacancy as $\mathrm{F}$ centre. The normal exposure time for each pattern is in the region of five minutes depending on primary beam intensity and crystal quality. After an exposure the flat plate is precisely scanned by a well focused He-Ne beam (633 nm red laser) of $150 \mu \mathrm{m}$ diameter (STOE IPDS) resulting in an emitted blue fluorescence, the intensity of which is proportional to the number of absorbed X-ray photons. The blue photon is emitted by the return of the $\mathrm{Eu}^{3+}$ to $\mathrm{Eu}^{2+}$ caused by the released electron. An optical system within the laser scanning head collects the emitted fluorescence for detection by a phtomultiplier, integrated over a period of time and digitized by a $16 \mathrm{bit}$ ADC. Finally, the integrated pixel intensities are transferred to the system computer.

The scanning system is driven by a stepping motor which is synchronized with the ADC to ensure that the position of each pixel is exactly controlled during the readout process. The digitized image is read in about $200 \mathrm{~s}$ and consists of more than one million pixels. After that it is transformed within a few seconds into cartesian coordinates 
while the next image is exposed. After each read-out cycle the plate is erased by white light to return it to a normalized state thus ensuring a minimum uniform background.

Figure 2 shows the arrangement of the single crystal diffractometer using an imaging plate (IP) detector. The dashed lines demonstrate the variable distance crystal-IP. The radiation source may be a sealed tube or rotating anode. A planar graphite monochromator and collimators of 0.3 to $1 \mathrm{~mm}$ diameter are used. A beam stop is mounted between crystal and plate on a very thin, non-absorbing polymer foil.

Table 1 gives a summary of characteristics of both the IP (1a) and the complete STOE Imaging Plate Diffraction System (1b). The following features of an imaging plate allow to get images of high quality:

- High quantum effiency for $\mathrm{X}$-rays (Mo and $\mathrm{Cu}$ radiation) of about $100 \%$.

- The photo-stimulated luminescence (PSL) is induced by a laser, which is in principle working without any divergence, thus ensuring a high resolution.

- The spectrum of the PSL is in the region of 300 to $500 \mathrm{~nm}$, in which the photomultiplier works with the highest effiency.

- The wavelength of the PSL $(\lambda=390 \mathrm{~nm})$ is well separable from the stimulating laser light $(\lambda=633 \mathrm{~nm})$.

- The induced latent image is stored for a long time (half live time about $10 \mathrm{~h}$, depending on temperature).

- This behaviour allows to separate exposure and read-out station.

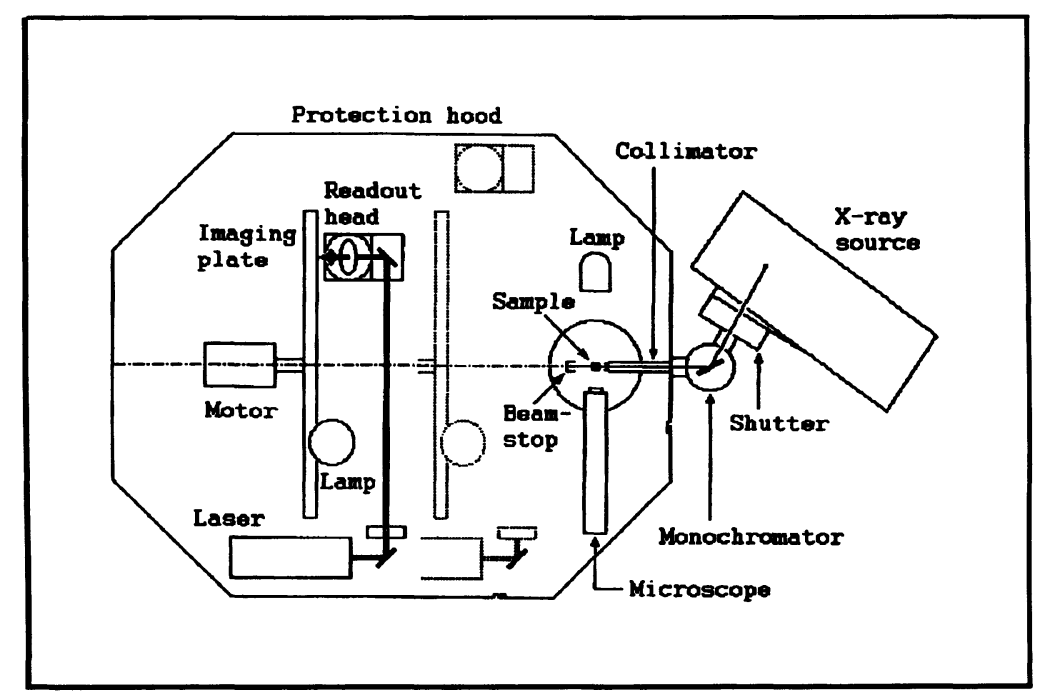

Figure 2 Arrangement of the IPDS for single crystal measurements (and for the transmission mode). 
Table 1 Technical data of the Imaging Plate (1a) and the STOE Imaging Plate Diffraction System (1b).

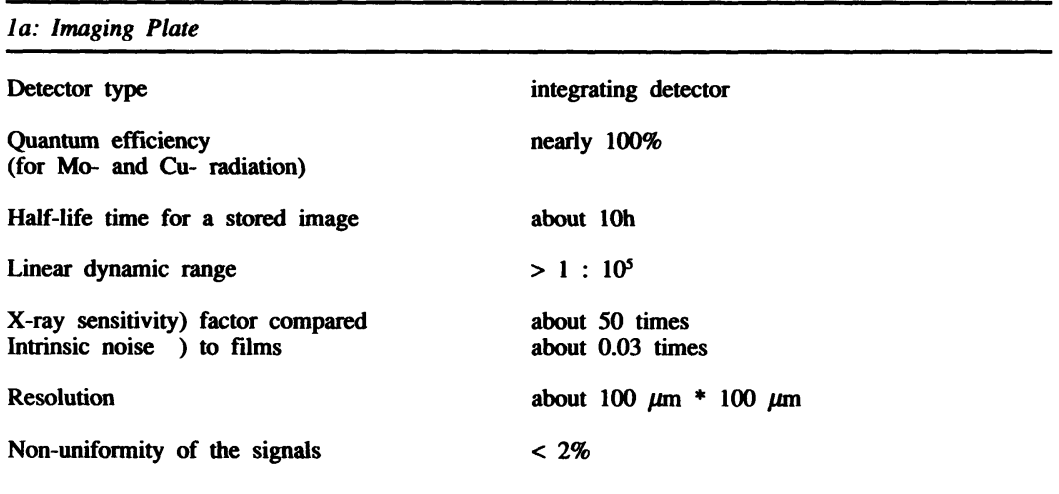

Ib: STOE IPDS

\section{Crystal to plate distance}

Maximum $2 \theta$

Minimum d/Å

Oscillation axis

Axis drive

Laser excitation beam

Luminescence detector

Read-out time (incl. erase)

Pixel size

Diameter of IP

Number of pixels

Output image data

Dimensions

Weight (without protection hood)
40 to $200 \mathrm{~mm}$ ( 40 to $450 \mathrm{~mm}$ on request)

$66^{\circ}$ (at a distance IP-sample of $40 \mathrm{~mm}$ )

$0.64(\mathrm{Mo}-\mathrm{K} \alpha), 1.41(\mathrm{Cu}-\mathrm{K} \alpha)$

vertically mounted, variable height

stepping motor, $0.002 \% / \mathrm{step}$

$15 \mathrm{~mW}$ He-Ne laser $(\lambda=632 \mathrm{~nm})$

photomultiplier tube system

about 200s

$150 \mu \mathrm{m} * 150 \mu \mathrm{m}$

$180 \mathrm{~mm}$

1.1 million

$2.2 \mathrm{MB}$

$90($ or 115$) \mathrm{cm}^{*} 80 \mathrm{~cm} * 60 \mathrm{~cm}$

about $85 \mathrm{~kg}$

\section{USE FOR SINGLE CRYSTAL DIFFRACTOMETRY}

The range of applications of the IPDS for single crystal investigations is shown e.g. in the given references (Fenske and Steck, 1993; Fuchs et al., 1993; Schütt et al., 1993; 
Auner and Weis, 1994; Paulus et al., 1994; Sheldrick et al., 1995) and includes metalorganic clusters, organic compounds, inorganic crystals and proteins. Twinned crystals, disordered structures and incommensurate crystals also may be investigated.

The IPDS allows to perform a complete structure solution in about one day. It starts with easy routines for accurate calibration, a convenient diffractometer control and a clear visualization of images. An automated peak search providing up to 2000 peak positions allows a powerful indexing of reflections without any prior lattice parameter or space group information. In many cases a complete indexing from only one orienting image is possible. An automatic cell reduction and cell transformation is provided. A further advantage is the fast integration of reflection with e.g. both automated refinement of orientation matrix after each integration and recognition of overlapping regions. Crystal decomposition is corrected. The complete data reduction includes corrections for crystal and air absorption, Lorentz and polarization effects and the combination of partially recorded reflections. The intensity data are provided in SHELX format or they will be converted to others, on request. Easy mechanical matching of the crystal position on the $\varphi$ axis of the IPDS to that of the four circle diffractometer STADI 4 and the automated transformation of an IPDS orientation matrix into a STADI 4 matrix enables fast and convenient transfer of a crystal between the two single crystal diffractometers.

STOE IPDS application note IP/08 (see table 2) shows a comparison of the data collection conditions and results of the data evaluation and structure refinement of a strongly absorbing crystal $\left(\mu=177 \mathrm{~cm}^{-1}\right)$ with a conventional four circle STADI 4 diffractometer and the IPDS. Similar quality factors were reached. The time for obtaining the orientation matrix and the intensity data set was much shorter on the IPDS. The small volume increase of the cell obtained with the IPDS is consistent with the temperature difference between the two measurements (we thank Prof. Beck, Gie $\beta$ en for the preparation of the crystal and the STADI 4 measurement).

Some accessories are adaptable to the IPDS, especially a low temperature attachment, preferably the Oxford cryostream system. High pressure measurements where the sample is embedded in a high pressure cell are also possible, but more complicated because of X-ray absorption by the pressure cell itself, the reduced angular ranges of $\varphi$ and $2 \theta$, the small crystal dimensions and the number of possible reflections of the cell. Preferably $\mathrm{Mo}$ or $\mathrm{Ag}$ radiation is used for these investigations.

\section{USE OF IP FOR INVESTIGATION OF POLYCRYSTALLINE MATERIALS}

The use of an Imaging Plate in powder diffractometry has some remarkable advantages. The fast and improved data processing is based on the simultaneous measurement of whole Debye- Scherrer cones. Both a coarse grained state and preferred orientation of the sample are quickly visible. The intensity of a reflection may be determined over the whole cone or sectors and then used for further 'normal' data handling. The IP technique allows phase analysis (Sasaki, et al. 1994a), stress (Schubert et al., 1993; Schubert et al., this issue) and texture (Brokmeier and Ermrich, 1993; Brokmeier, this issue) determination, also within very small regions. High pressure powder investigations and time-resolved studies of phase transitions are described e.g. in (Nelmes and McMahon, 1994; Sasaki et al., 1994b). Other applications are measurements of crystal orientation (Laue images) e.g. due to further handling (cut of crystals) and determination of angles between single grains. 
Table 2 Data collection conditions and results of the data evaluation and structure refinement

\begin{tabular}{ll}
\hline STADI4 & IPDS \\
\hline
\end{tabular}

Crystal dimensions

Crystal attachment

Space group

Number of formula units/cell

Sum formula

Temperature

Lattice constants

Cell volume

Calculated density

Primary beam

Determination of orientation matrix

Data collection

Recorded reflections

$\mathbf{R}_{\text {merge }}$

Unique reflections

$2 \theta$ range for refinement

Reflections for refinement

Refined parameters

Absorption correction

Linear absorption coefficient

Extinction correction

Extinction coefficient

Quality factors

$0.16 \cdot 0.20 \cdot 0.36 \mathrm{~mm}^{3}$

Enclosed in a capillary and fixed with little grease

$$
\begin{gathered}
P 2_{1} / c \\
Z=4
\end{gathered}
$$

\section{$\mathrm{WTe}_{3} \mathrm{Cl}_{\mathbf{6}} \mathrm{I}$}

$203 \mathrm{~K}\left(-70^{\circ} \mathrm{C}\right)$

$295 \mathrm{~K}\left(22^{\circ} \mathrm{C}\right)$

$$
\begin{aligned}
& a=1156.3(3) \mathrm{pm} \\
& \mathbf{b}=1056.1(2) \mathrm{pm} \\
& \mathrm{c}=1159.8(2) \mathrm{pm} \\
& \beta=112.33(2) \mathrm{deg} .
\end{aligned}
$$

$1310.0 \cdot 10^{6} \mathrm{pm}^{3}$

$$
\rho=4.59 \mathrm{~g} \cdot \mathrm{cm}^{-1}
$$

Sealed Mo tube $1 \mathrm{~kW}(50 \mathrm{kV}, 20 \mathrm{~mA})$ Plane graphite monochrom. $\lambda=71.073 \mathrm{pm}(\mathrm{Mo}-\mathrm{K} \alpha)$

$0.8 \mathrm{~mm}$ collimator

Random search of 25 reflections and indexing, total time about $90 \mathrm{~min}$. Tabulated cell parameters determined later with 60 reflection positions at negative and positive $2 \theta$,

$$
13^{\circ}<2 \theta<47^{\circ}
$$

$$
\omega / \theta \text { scan }
$$$$
3^{\circ}<2 \theta<60^{\circ}
$$

$123 \mathrm{~h}$ total recording time (65 $\mathrm{s}$ average counting time for a reflection)

$$
\begin{gathered}
6818 \\
2.0 \% \\
3824 \\
3^{\circ}<2 \theta<60^{\circ} \\
3553 \text { with } \mathrm{I}>1 \text { o(I) }
\end{gathered}
$$

100 $\mathrm{a}=1156.5(6) \mathrm{pm}$

$\mathrm{b}=1059.2(4) \mathrm{pm}$

$\mathrm{c}=1162.3(6) \mathrm{pm}$ $\beta=112.40(4) \mathrm{deg}$.

$1316.4 \cdot 10^{6} \mathrm{pm}^{3}$

$\rho=4.57 \mathrm{~g} \cdot \mathrm{cm}^{-1}$

Sealed Mo tube $1 \mathrm{~kW}(50 \mathrm{kV}, 20 \mathrm{~mA})$ Plane graphite monochrom. $\lambda=71.073 \mathrm{pm}(\mathrm{Mo}-\mathrm{K} \alpha)$ $0.5 \mathrm{~mm}$ collimator

Detector distance $50 \mathrm{~mm}$ $11^{\circ}<2 \theta<61^{\circ}$

20 min total recording time 2 images, $\Delta t=3 \mathrm{~min}$

$\varphi=0$ and $90^{\circ}, \Delta \varphi=0.1^{\circ}$

183 reflection positions

$<5$ min processing time for peak search and indexing

Detector distance $50 \mathrm{~mm}$ $11^{\circ}<2 \theta<61^{\circ}$

12.4 h total recording time 82 images, $\Delta \mathrm{t}=5 \mathrm{~min}$, $\varphi=0$ to $164^{\circ}, \Delta \varphi=2^{\circ}$, oscill.

\section{0 \\ $1.9 \%$}

3749

$11^{\circ}<2 \theta<56^{\circ}$

2812 with $F_{0}>6 \sigma\left(F_{0}\right)$

100

Numerically, description of crystal shape by 14 faces

$$
\mu=178 \mathrm{~cm}^{-1}
$$

$$
\mu=176 \mathrm{~cm}^{-1}
$$

LARSON method in consideration of the individual path length for each reflect.

Correction by expression: $F_{c, \text { orr }}=F_{c}\left(1-\varepsilon F_{c}^{2} \sin ^{-1} \theta\right)$

$$
\varepsilon=5440(95) \quad \varepsilon=5.8(1) \cdot 10^{-8}
$$

$\mathbf{R}=2.1 \%, \mathbf{R}_{\mathrm{w}}=1.7 \%$ 
Our IPDS powder diagrams can be loaded and evaluated by the STOE powder software package VISUAL $X^{\text {POW }}$. Note, that also rectangular IP's may be used and that whole backscattered cones may be obtained.

For complete single crystal data sets the IPDS is used in the way described above. If, however, informations about single crystals, powder samples, polymeres etc. are required which can be obtained either from only one or from a limited number of exposures, an exposure station (see figure 3) can be used on which light protected IP for transmission or backscattering investigations can be mounted. The exposure station allows to use various sample holders providing the necessary motions. The exposed IP's are then transferred to the IPDS for normal read-out procedure. If wanted a number of exposure stations can be combined with one IPDS. For backscattering experiments the beam passes the hole in the image plate centre. The $2 \theta$ region of a diffracted diagram can be changed depending on the variable distance IP-sample and is e.g. about $2 \theta=$ 123.5 to $170.5^{\circ}$ for a distance of $60 \mathrm{~mm}$ (backscattering mode) and $2 \theta=2.3$ to $42^{\circ}$ for a distance of $100 \mathrm{~mm}$ (transmission mode).

\section{Powder measurements}

Two measurements are shown.

Figure 4a shows a picture of quartz powder. The powder was investigated in a continuously rotating $0.5 \mathrm{~mm}$ capillary. The exposure time was $5 \mathrm{~min}$ (Mo $\mathrm{K}_{\alpha}$ radiation, $\mathrm{U}=50 \mathrm{kV}, \mathrm{I}=40 \mathrm{~mA}$, collimator $0,5 \mathrm{~mm}$ ). Using a distance IP - sample of $\mathrm{D}=$

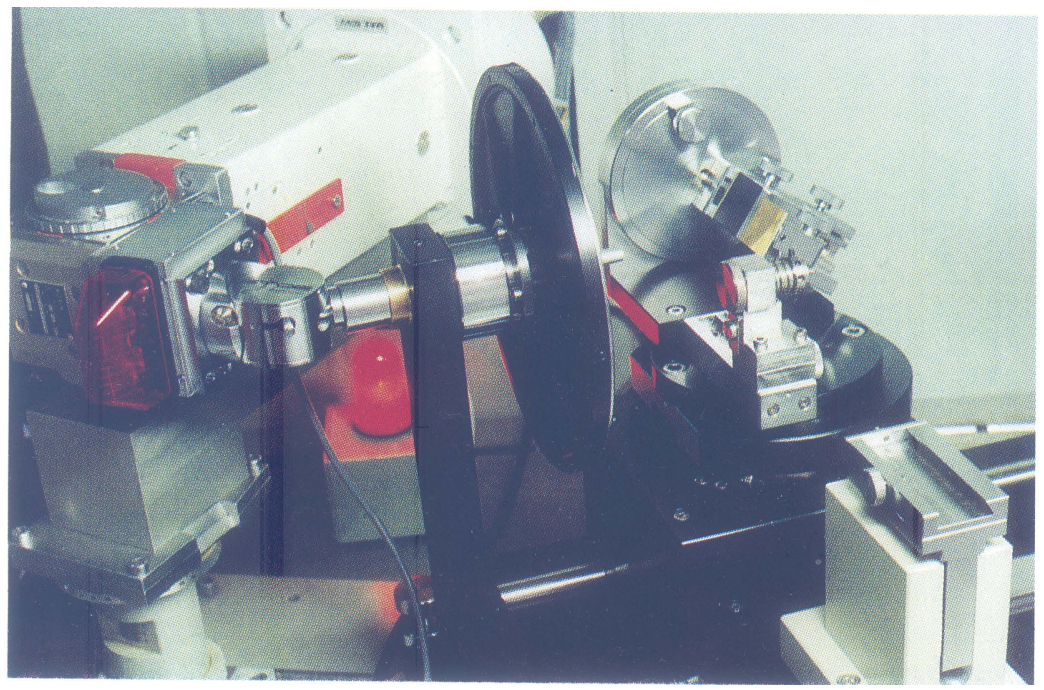

Figure 3 Backscattering arrangement of the IP, 'exposure station'. (See Color Plate 10). 

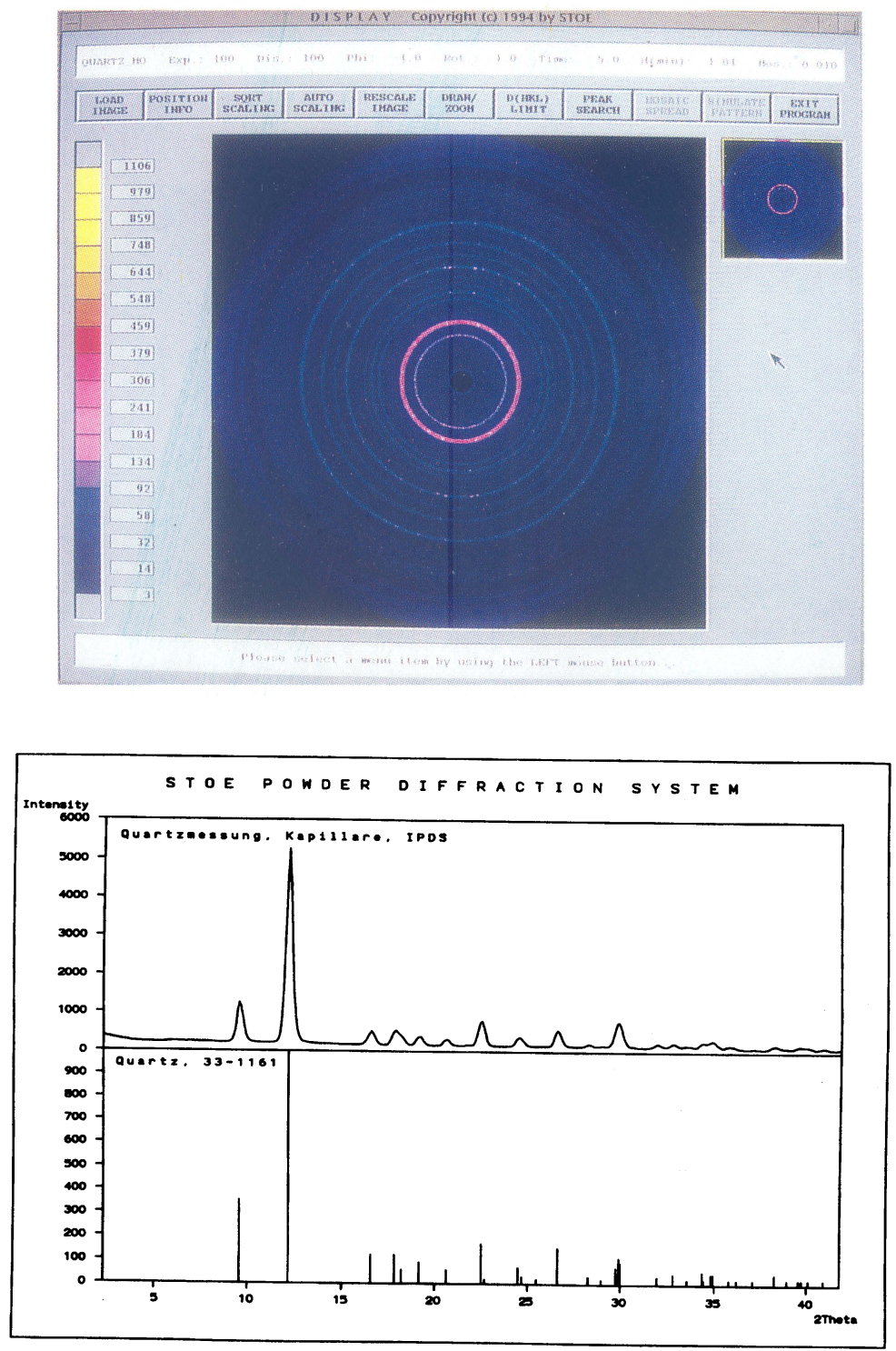

Figure 4 Quartz powder measurement a) whole cones and b) addition of the intensities over the whole cones. (See Color Plate 11). 
$100 \mathrm{~mm}$ a $2 \theta$ - region of about 2.3 to $40^{\circ}(\Delta \mathrm{d}=17.78$ to $0.990 \AA)$ was observed. The data were integrated over the whole Debye- Scherrer cone and included in the VISUAL $X^{\text {POW }}$ software package. The plot is shown in Figure $4 \mathrm{~b}$. This kind of measurements allows a very quick overview about the quality of a powder (the existing coarse grained state, preferred orientation) and shows the possibility to carry out a qualitative phase analysis.

Figure 5a shows a picture of silicon powder. The powder was filled into a $0.5 \mathrm{~mm}$ capillary. The exposure time was 2 hours using a collimator of $0.5 \mathrm{~mm}$ diameter (Mo- $K_{\alpha}$ radiation, $\mathrm{I}=\mathbf{4 0} \mathrm{mA}, \mathrm{U}=34 \mathrm{kV}$ (without $\lambda / 2$ ). Complete diffraction cones were used for integration. The speciality of this measurement is the detection of the forbidden $\mathrm{Si}(222)$ reflection (see Figure 5b).

\section{Stress measurement}

The method is based on the determination of angular differences of the same reflections between two exposures at different $\psi$ angles or to an unstressed state or powder diffraction cone.

The use of an imaging plate has several advantages for stress analysis:

- both the transmission and the backscattering mode (for the high $2 \theta$ values) are available.

- fast and better analysis of coarse grained material using intensity integration over the whole Debye-Scherrer cone or selected sectors.

- improved stress determination for textured materials using intensity measurements of sectors including the reflections of preferred orientations.

- simultaneous investigation of diffraction cones of different reflections in one measurement.

A typical backscattering arrangement of the IP and a tilted sample are shown in Figure 3. A ground ferritic steel was investigated using a conventional sealed tube $\left(\mathrm{Cr}-\mathrm{K}_{\alpha}\right.$ radiation, $\mathrm{U}=40 \mathrm{kV}, \mathrm{I}=25 \mathrm{~mA}$ ) and a graphite monochromator (Schubert et al., 1993). The distance between the imaging plate and the sample was $100 \mathrm{~mm}$ which corresponds to an observed region of $2 \theta=138^{\circ}$ to $174^{\circ}(\Delta \mathrm{d}=1.227$ to $1.147 \AA)$. A collimator of $2 \mathrm{~mm}$ was fixed in the hole of the imaging plate and guides the primary beam between the monochromator and the sample. The exposure time was $60 \mathrm{~min}$. The investigations were carried out at the institute of the Fraunhofer Gesellschaft in Chemnitz. We thank Dr. Kämpfe, Dr. Schubert and co-workers and also Dr. Tränkner for the software.

\section{Texture measurement}

The use of the imaging plate for texture analysis has two main advantages. On the one hand the imaging plate allows to get a qualitative impression of preferred orientations of a number of Bragg reflections with only one exposure and on the other hand the resolution is much better compared to the usual techniques.

Figure 6 shows the diffraction picture of an aluminium foil. The measurements were carried out in transmission geometry, with a conventional sealed tube $(U=40 \mathrm{kV}$, $\mathrm{I}=40 \mathrm{~mA}, \mathrm{Mo}-\mathrm{K}_{\alpha}$ radiation, $\lambda=0.7107 \AA$ ), a graphite monochromator and a diaphragm 


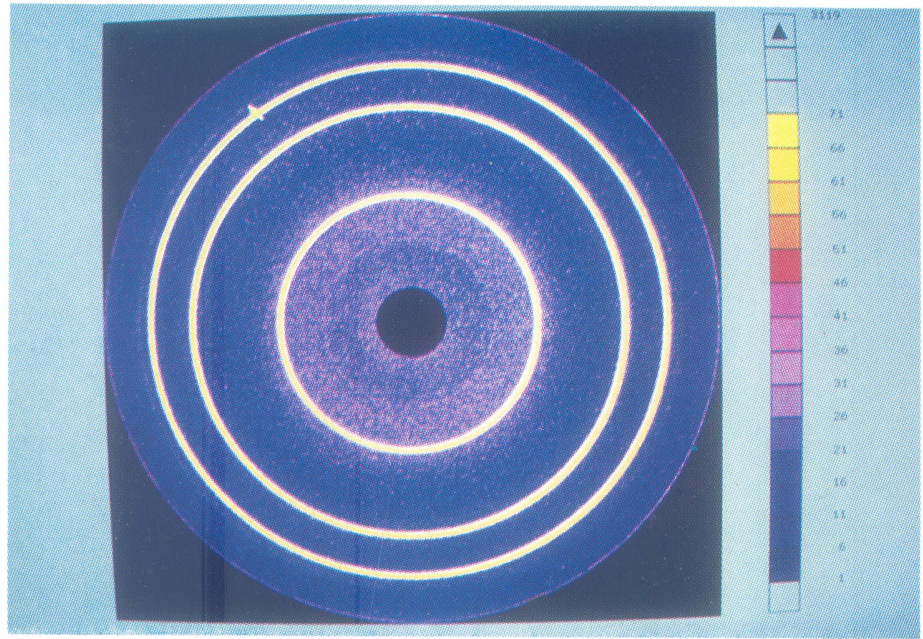

(a)

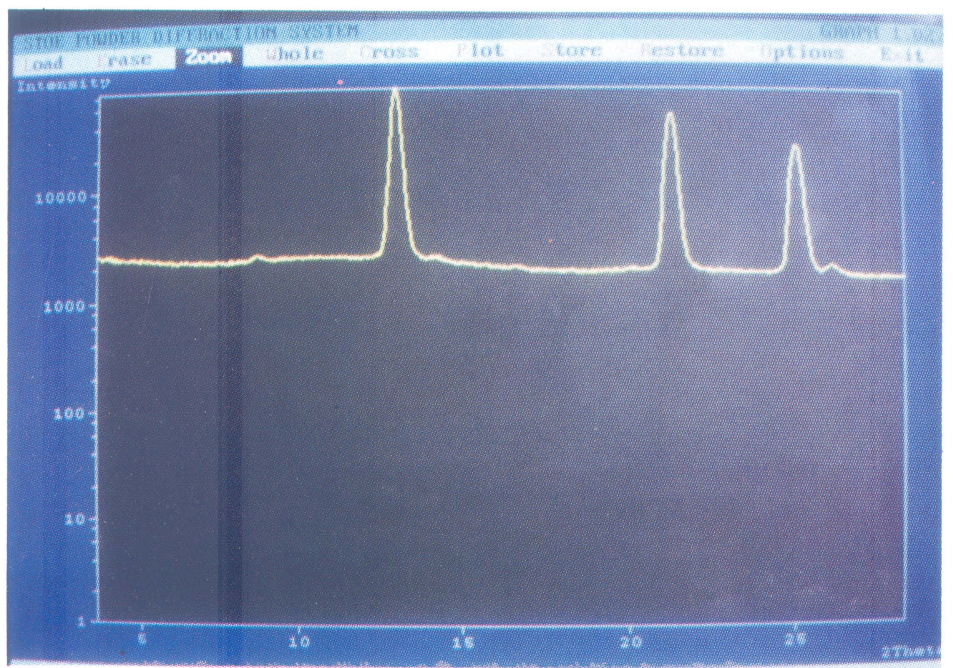

(b)

Figure 5 Silicon powder measurement for detection of the forbidden $\mathrm{Si}(222)$ a) whole cones and b) addition of the intensities over the whole cones. (See Color Plate 12). 


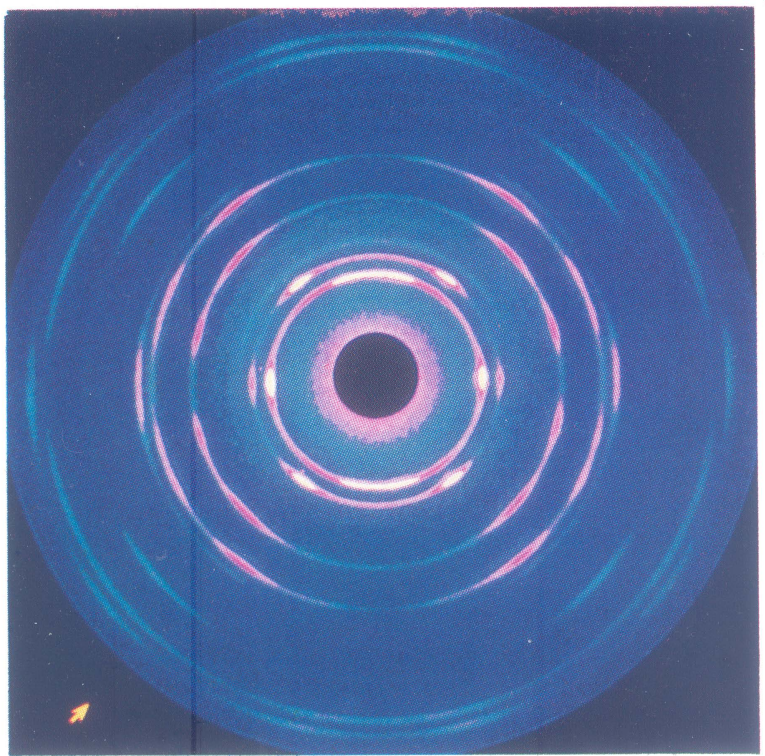

Figure 6 Diffraction image of an aluminium foil in transmission mode at the 'exposure station'. (See Color Plate 13).

of $1 \mathrm{~mm}$ diameter. At first a transmission measurement was used to get basic information. The foil was positioned perpendicular to the primary beam. The exposure time was $300 \mathrm{sec}$. Because of a sample-to-detector distance of $80 \mathrm{~mm}$ a $2 \theta$ range between 7.1 to $48.4^{\circ}$ was covered ( $\Delta d=5.72$ to $0,87 \AA$ ). Table 3 shows the good agreement between calculated and measured relative intensities (an integration over the whole DebyeScherrer cone). Then the texture measurement method described by Cluster (1948) was employed. The sample-to-detector distance was changed to $70 \mathrm{~mm}\left(2 \theta=8.1\right.$ to $\left.52.1^{\circ}\right)$. A total of 9 exposures ( $300 \mathrm{~s}$ per exposure) were made to cover a quarter pole figure. The angle between the primary beam and the plane of foil was fixed to $8.7^{\circ}$, and the sample was titled in 9 steps of $10^{\circ}$ around the foil normal. A comparison of the high

Table 3 Comparison of calculated and measured relative intensities of the $\mathrm{Al}$ foil.

\begin{tabular}{lcc}
\hline$h k l$ & \multicolumn{2}{c}{$I(h k l) / I(111)$} \\
& calculated & measured \\
\hline 111 & 100 & 100 \\
200 & 50.3 & 53.2 \\
220 & 35.9 & 44.8 \\
311 & 42.0 & 50.8 \\
222 & 12.0 & 14.1 \\
\hline
\end{tabular}


density distribution in the Debye-Scherrer cone of the (111) reflection against the neutron experiment demonstrates the excellent resolution of the Imaging Plate. In the case of the neutron diffraction the measurement of the Debye-Scherrer circle was carried out in steps of $1^{\circ}$. Hence, the $\mathrm{X}$-ray data were restricted to the same theoretical resolution by a mathematical smoothing (see Figure 7). It should be pointed out that in the case of X-ray diffraction one section of the foil was considered, whereas in the case of neutron diffraction a sample composition of 176 individual sections took part in the scattering experiment. We thank Dr. Brokmeier, Geesthacht for data analysis, calculations and the comparison to his neutron measurements (Brokmeier and Ermrich, 1993; Brokmeier, this issue).
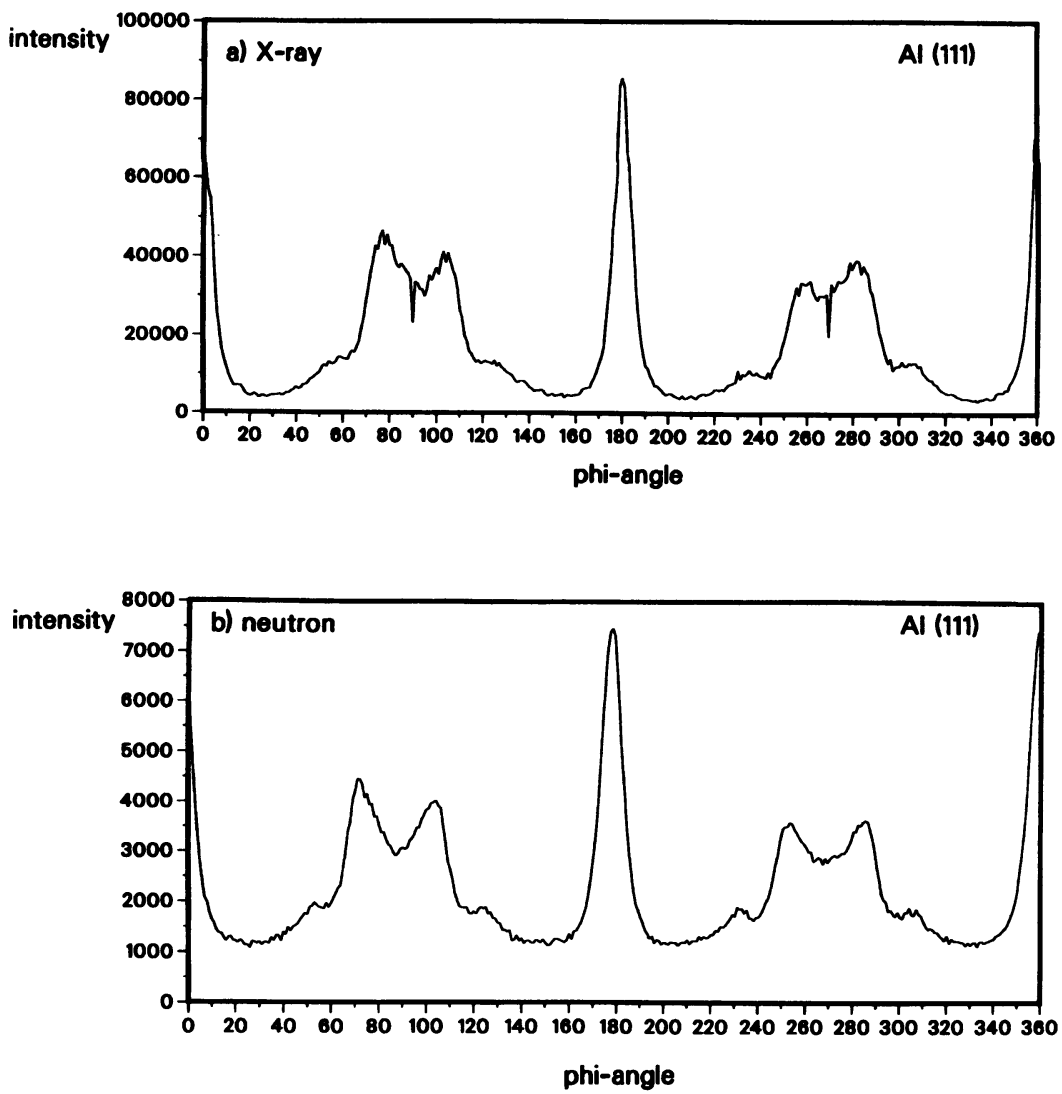

Figure 7 Comparison of resolution a) X-ray measurement using IP b) neutron experiment. 


\section{CONCLUSIONS}

The Imaging Plate is a very convenient powerful two-dimensional detector. Special sample holders are easy adaptable. It can be used for measurements both of single crystals and of polycrystalline materials. Investigating single crystals it requires only a fraction of time against 4-circle diffractometers. Using several Imaging Plates on different exposure stations for investigations of powders and for stress and texture measurements, the IPDS works as read-out station.

\section{References}

Auner, N. and Weis, J., (Editors) (1994). Organosilicon Chemistry. From Molecules to Materials, VCH, Weinheim, 165-166.

Brokmeier, H.-G. and Ermrich, M. (1993). "A new method for texture measurement based on an Xray Imaging Plate system", Proc. of EPDIC 3, Wien.

Brokmeier, H.-G. "The Image Plate technique in X-Ray texture analysis", this issue.

Cluster, J. F. H. (1948). Physica, 14, 453-474.

Ermrich, M. and Wölfel, E. R. (1994). "Use of Position Sensitive Detectors and Imaging Plates in X-ray analysis", Sbornik prispevku kolokvia Krystalograficke spolecnosti, VSB Ostrava-Poruba, pp. 37-52.

Fenske, D. and Steck, J.-C. (1993). "Neue Cu-Te-Cluster", Angew. Chem., 105, 254-257.

Fuchs, R., Habermann, N. and Klüfers, P. (1993). "Sandwichartige Mehrkernkomplexe", Angew. Chemie $105,895-897$.

Miyahara, J. and Kato, H. (1984). "Photostimulated Luminescence (PSL) and Color Centers in BaFX:Eu+ (X=Cl, Br, J) Phosphors”, Jpn. Soc. Appl. Phys., 53, 884-890.

Nelmes, R. J. and McMahon, M. I. (1994). "High-Pressure Powder Diffraction using an Image-Plate Area Detector", Adv. in X-ray Analysis, Vol. 37, 419-432, Edited by J. V. Gilfrich et al., Plenum Press, New York.

Paulus, E. F., Dornberger, K., Werner, W. and Fenske, D. (1994). "Madurahydroxylactone”, Acta Cryst., C50, $2064-2067$.

Sasaki, K., Hirose, Y. and Sasaki, T. (1994a). "Measurement of Retained Austenite in Stainless Steel using Imaging Plate", Adv. in X-Ray Analysis, Vol. 37, 483-490, Edited by J. V. Gilfrich et al., Plenum Press, New York.

Sasaki, K., Yamazaki, H., Masuda, K. and Hsiue, G. (1994b). "The development of a Time-Resolved X-Ray Measurement System using Imaging Plate" Adv. in X-Ray Analysis, Vol. 37, 385-393, Edited by J. V. Gilfrich et al., Plenum Press, New York.

Schubert, A., Kämpfe, B., Ermrich, M., Auerswald, E. and Tränkner, K. (1993). "Use of an X-ray Imaging Plate for Stress Analysis", Proc. of EPDIC 3, Wien.

Schubert, A., Kämpfe, B. and Goldenbogen, S. "X-Ray stress analysis by use of an area detector", this issue.

Schütt, W., Herdtweck, E., Hahn, F. and KreißI, F. R. (1993). "Darstellung und Röntgenstrukturuntersuchung von...", J. Organomet. Chem., 443, C33-C36.

Sheldrick, G. M., Paulus, E., Vertesy, L. and Hahn, F. (1995). "Structure of Ureido-Balhimcyin", Acta Cryst., B51, 89-98.

Takahashi, K., Miyahara, J. and Shibahara, Y. (1985). "Photostimulated Luminescence (PSL) and Color Centers in BaFX:Eu ${ }^{2+}(\mathrm{X}=\mathrm{Cl}, \mathrm{Br}, \mathrm{J})$ Phosphors", J. Electrochem. Soc., 132, 1492.

Wölfel, E. R. (1981). “A New Focusing Monochromatic-beam Diffractometer using a linear PositionSensitive Detector”, J. Appl. Cryst., 15, 291-296.

Wölfel, E. R. (1983). "A Novel Curved Position-sensitive Proportional Counter for X-ray Diffractometry", J. Appl. Cryst., 16, 341-348.

Wölfel, E. R., Baumgartner, B., Dollmann, B., Ermrich, M., Hahn, F. and Langhof, H. et al. (1992). "STOE Automatic X-Ray Powder Diffractometer Systems", STOE Appl. Lab. 